\title{
Desiccation facilitates wave-induced mortality of the intertidal alga Fucus gardneri
}

\author{
R. Nicholas Haring ${ }^{1}$, Megan N. Dethier ${ }^{2, *}$, Susan L. Williams ${ }^{3}$ \\ ${ }^{1}$ Department of Biology, California State University, Northridge, Northridge, California 91330, USA \\ ${ }^{2}$ Friday Harbor Laboratories, University of Washington, Friday Harbor, Washington 98250, USA \\ ${ }^{3}$ Bodega Marine Laboratory, University of California at Davis, Bodega Bay, California 94923-0247, USA
}

\begin{abstract}
Physical factors such as desiccation and water motion can influence the abundance and performance of intertidal seaweeds. We addressed the hypothesis that the intertidal seaweed Fucus gardneri can be dislodged or damaged by relatively small waves if weakened by the effects of desiccation. Stress-strain curves generated for desiccated and hydrated thalli revealed that desiccated stipes were more brittle than hydrated stipes and required less total work (energy) to break. Results from a dynamic loading experiment suggest that the oscillating motion of the waves may be an important factor in breaking brittle stipes. Therefore, seemingly benign water motion may provide sufficient force to damage or dislodge desiccated thalli. In the late spring and summer in this area, waves are generally small but desiccating conditions are common as low tides fall during midday. Mortality of field populations is high during these seasons; thalli experimentally protected from desiccation suffered many fewer losses. However, desiccated F. gardneri can rehydrate rapidly (less than $1 \mathrm{~min})$, minimizing the window of time that wave forces can break stipes. This study provides an example of how 2 sub-lethal physical factors, desiccation and benign waves, can interact to cause mortality in an upper intertidal seaweed.
\end{abstract}

KEY WORDS: Desiccation - Biomechanics - Fucus gardneri - Wave forces - Population growth · Mortality

Resale or republication not permitted without written consent of the publisher

\section{INTRODUCTION}

The individual effects of wave forces and desiccation on intertidal macroalgae have been well studied (reviewed by Davison \& Pearson 1996, Hurd 2000). Studies on the effects of desiccation generally have focused on its impacts on photosynthetic performance, growth, and distribution (reviewed by Chapman 1995). Bell (1993) suggested that desiccation and heating ultimately can influence growth rates of Mastocarpus papillatus by limiting photosynthesis, while Schonbeck \& Norton (1980) found tissue necrosis and curtailment of growth in 2 species of fucoids desiccated in the laboratory. Kraemer (1990) measured material properties of Iridaea cordata (now Mazzaella splendens) over

${ }^{*}$ Corresponding author. E-mail: mdethier@u.washington.edu a range of water loss and found that breaking strain decreased and stiffness increased when fully desiccated. However, little is known of the combined effects of desiccation and wave forces on intertidal seaweeds and their impacts on seaweed populations.

Studies on the effects of water motion have examined how the size, morphology, and/or flexibility of macroalgae can mitigate damage induced by wave forces (Koehl \& Wainwright 1977, Denny et al. 1985, Carrington 1990, Dudgeon \& Johnson 1992, Gaylord et al. 1994, Hawes \& Smith 1995, Blanchette 1997). These studies have shown that acceleration, drag, and to a lesser extent lift exert important hydrodynamic forces on seaweeds (Gaylord 1999). Another force imposed on macroalgae exposed to waves in shallow water is bi-directional dynamic loading due to drag from oscillating water motion, which can weaken the thallus over time, making it more prone to breaking. Dynamic 
loading increases stress on 2 subtidal seaweeds with rigid stipes, Eisenia arborea and Pterygophora californica (Gaylord \& Denny 1997). Intertidal macroalgae experience dynamic loading when they are reimmersed with the returning tide. However, the effect of wave-induced dynamic loading on the damage or dislodgment of intertidal seaweeds has not yet been addressed experimentally.

Fucus gardneri is an abundant alga on San Juan Island, Washington, dominating the high- to mid-intertidal zone. During the summer months, F. gardneri thalli can be exposed to air for periods of $10 \mathrm{~h}$ and can lose more than $60 \%$ of its field mass due to desiccation (Williams \& Dethier unpubl. data). Desiccation can leave thalli crisp and brittle and presumably alters the strength and elastic properties of the thallus and stipe. Water motion during the summer is relatively benign on San Juan Island due in part to protection from other land masses and to the low frequency of storms. However, rafts of F. gardneri thalli sometimes wash up on shore, suggesting that they can be damaged and/or dislodged by wave forces. Thalli in these rafts are often broken at the stipe (lacking a holdfast). In the intertidal, one can find broken stipes, lacking blades and branches but still attached by the holdfast (pers. obs.). We addressed the hypothesis that F. gardneri can be dislodged or damaged by relatively small wave forces if the effects of desiccation have weakened the material properties of the stipe.

\section{MATERIALS AND METHODS}

Laboratory work was conducted at the Friday Harbor Laboratories (FHL) on San Juan Island, Washington $\left(48^{\circ} 30^{\prime} \mathrm{N}, 123^{\circ} 10^{\prime} \mathrm{W}\right)$. Field work was conducted in the rocky intertidal zone near FHL; this shoreline is protected from oceanic swell but is exposed to tidal currents, boat wakes, and small wind waves. Experiments in the 'high' zone were at ca. $+1.5 \mathrm{~m}$ above mean lower low water (MLLW), and in the 'mid' zone at ca. $0.5 \mathrm{~m}$ above MLLW.

Laboratory experiments. Stress and strain on Fucus gardneri stipes: To quantify relevant material properties of hydrated and desiccated Fucus gardneri, stipes were pulled with a tensometer at a rate of $10 \mathrm{~cm} \mathrm{~min}^{-1}$ until they broke. This simultaneously measured the force required to break the stipe and the deformation in length before breaking. Hydrated (submerged) thalli were haphazardly collected from the intertidal and prepared for stress-strain analysis. Half were randomly selected to remain hydrated in a sea table, while the remainder were returned to dry rocks in the upper intertidal and allowed to desiccate for $6 \mathrm{~h}$. Immediately prior to analysis, the blades were cut from the thalli, leaving only the stipe.
Stipes were placed into the tensometer by clamping each end between 2 small Plexiglas ${ }^{\mathrm{TM}}$ plates padded with neoprene. The plates were compressed together using clamps and tightened enough to grip each end of the stipe without weakening the attachment points. Cyanoacrylic Superglue ${ }^{\circledR}$ catalyzed with sodium bicarbonate was applied to the stipe ends and sandwiched between the neoprene-lined plates to prevent the stipes from slipping out of the clamp. Only data from stipes that broke outside the clamps were used for stress-strain analysis.

Stress (force/cross-sectional area) and strain (extended stipe length normalized to initial length, $\left.\left[l-l_{i}\right] / l_{i}\right)$ at failure were measured and the elastic modulus (stress/strain) at failure was calculated (see Koehl \& Wainwright 1986, Biedka et al. 1987, and Denny et al. 1989 for further discussion of mechanical tests). Work per volume required to break the stipe was estimated by approximating the area under the stressstrain curves, and the total work required to break the stipe was calculated from that value. Volume of the stipe was estimated by approximating a geometric cylinder using the stipe length and diameter measured prior to analysis. These biomechanical data were compared for desiccated and hydrated stipes using Student's $t$-tests after testing for assumptions of normality and homoscedasticity. Data for work per volume and total work were square-root-transformed and data for strain were log-transformed. Means and standard errors are reported for untransformed data.

Dynamic loading of Fucus gardneri stipes: To test how desiccation affects stipe-breaking, thalli were subjected to dynamic loading using an apparatus designed to simulate the bending experienced in waves (Fig. 1). The thalli were placed into the apparatus erect and gripped at the stipe near the holdfast using a neoprene-lined clip fixed to the laboratory table. The blades of the thallus were encircled by a loop of surgical tubing that held the thallus in place and subjected it to an oscillating load. The length of tubing was fixed to a stationary post on one end, looped in the middle, and attached to a swivel arm on a Plexiglas $^{\mathrm{TM}}$ disk rotated by a DC motor at the other end. With the help of cylindrical guides, the tubing translated the cyclical motion of the motor into a bi-directional oscillation. Thalli were flopped back and forth at a force of $1.59 \mathrm{~N}$ at 80 cycles $\mathrm{min}^{-1}$. The bending force and rate of the loader were somewhat constrained by the materials avaiable at the time of the experiment. Speed of the motor was kept high to compensate for the lack of torque needed to move the thalli. However, we were satisfied with the output of the device, as it probably produced a force experienced by thalli in the field and approximated the speed of the first incoming waves. 
A. Top view

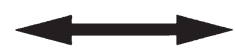

B. Side view

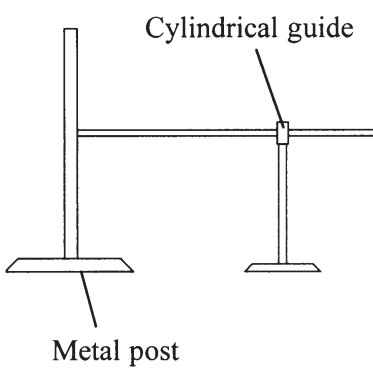

Fig. 1. Schematics of the dynamic loader

Ten desiccated and 10 hydrated thalli (prepared in the same manner as those used for stress-strain analysis) were tested in the loader separately and the mean number of cycles required to break the stipes was recorded.

Rehydration of desiccated thalli: We estimated the rehydration rate of Fucus gardneri by submerging desiccated thalli into a sea table and measuring increase in wet weight over time. First, thalli were hydrated fully for $24 \mathrm{~h}$, blotted dry and weighed. Hydrated thalli were placed in a wind tunnel under a heat lamp $\left(29^{\circ} \mathrm{C}\right)$ for $6 \mathrm{~h}$ to simulate desiccation in the field. Desiccated thalli were reweighed and placed in a sea table for a second hydration. Five thalli were removed from the water at intervals from 0.5 to $30 \mathrm{~min}$, blotted dry and weighed immediately. The percent increase in mass was calculated and used as a proxy for water uptake.

Field experiments. Flow characterization: We estimated summertime water flow speeds by placing 3 maximum wave force dynamometers (modified from Bell \& Denny 1994) among the Fucus gardneri at 1 site in the intertidal. Care was taken during construction of the dynamometers to install more compliant rubber bands, instead of springs, to accurately record wave speeds at or below $2.5 \mathrm{~m} \mathrm{~s}^{-1}$. By selecting the correctsized rubber bands we were able to record maximum wave speeds at the site without reaching the maximum measurement limit of the devices. The dynamometers were checked daily and maximum values were recorded between 11 and 17 August 2000. The means for each dynamometer were pooled to give an overall estimation of maximum flow speed during this period. Much larger waves occur at this site during fall and winter storms, but there is no desiccation during these seasons because the low tides fall at night (see 'Results').

Desiccation rates: The observations that led us to consider a biomechanical study were changes in the physical environment that occurred as field mortality apparently increased from spring through summer. During this time, 3 key changes contribute to desiccation of intertidal thalli: (1) air temperature increases; (2) rainfall declines; and (3) the lower low tides (in this very mixed semidiurnal system) gradually switch from falling at night (October through February) to early morning (March and April) to midday (May through July).

Rates of desiccation of thalli in the field on a 'typical' warm summer day were measured on 28 July 1999. Beginning just after emersion at 07:00 h (high zone) or 08:30 h (mid zone), 20 thalli were collected every hour: 10 forming a top canopy and 10 from under a canopy. The thalli were weighed immediately, immersed in seawater overnight, and then blotted and reweighed. Degree of desiccation was calculated as the field mass/hydrated mass. Every 15 min temperature and humidity measurements were made near the collection sites throughout the emersion period with ruggedized probes and a datalogger (Models HMP36E and HMI38). To record the seasonal change in physical conditions, temperature data at a site near FHL were recorded frequently from January up to November 2000 both in the high and mid zone with TidbiT ${ }^{\mathrm{TM}}$ (Onset Computer) temperature dataloggers. Loggers were attached to a PVC plate bolted to the rock, with the glass readout nubs protected by a piece of tubing. The sensor was left uncovered, and algal canopies were kept clear.

Breaking strength of Fucus gardneri in the field: We tested the breaking strength of F. gardneri in the high intertidal zone, where desiccation is maximum, by dislodging haphazardly selected thalli with a $5 \mathrm{~kg}$ spring scale. We looped a soft nylon line around the blades just above the stipe, attached this line to the spring scale and pulled perpendicular to the substratum (in an attempt to reduce the number dislodged at the hold- 
fast) until the thallus detached. Thalli that broke at the holdfast were excluded from the analysis. The maximum force required to dislodge the thallus was recorded and the diameter was measured using calipers. The cross-sectional (cs) area at the breaking point was estimated by assuming a circular break and multiplying the squared radius by $\pi$.

To compare breaking strength (force/cs area) between hydrated and desiccated thalli, we dislodged separate thalli at 2 times during the tidal cycle: in the morning, just after aerial exposure (maximum hydration), and later in the day, just before the tide returned to immerse the thalli (maximum dehydration for that day). Thalli were exposed for $6 \mathrm{~h}$ on a sunny day, with air temperature just above the substratum reaching $32^{\circ} \mathrm{C}$.

Thallus size and dislodgment in the field: To assess what effect thallus size has on dislodgment, thalli broken or pulled from the rock by natural disturbances were quantified in July 2000; thalli in the drift zone from each of 5 beaches near FHL were haphazardly gathered from 1 spot until 100 thalli had been collected. Their lengths (longest branch) were measured, and the presence/absence of a holdfast was noted. Size distributions of thalli attached to the rock at 3 nearby sites were similarly quantified by measuring the first 50 thalli encountered in a mid-shore and a high-shore quadrat. Data from all sites and heights were pooled.

Natural mortality: Our original impetus for this study came from observations of apparently increased mortality of Fucus gardneri during the transition from spring to summer. Survivorship of thalli marked and measured (for other experiments) at various sites around San Juan Island (semi-protected to protected) was calculated in terms of percent losses of thalli per season (censused quarterly). Data were pooled for populations both in the high zone and the mid zone. In addition, the effects of desiccation on survivorship were tested in an experiment in the high zone near FHL. Here, 16 'awnings' consisting of 2 layers of fiberglass window-screening sewn onto a rigid plastic hoop $45 \mathrm{~cm}$ in diameter were held an average of $10.5 \mathrm{~cm}$ off the rock near the upper limit of the F. gardneri zone. Awnings were deployed in March 2000 and taken down in July. Under each awning and in 16 unmanipulated (no structure) control areas, we thinned the $F$. gardneri canopy to 40-60\% cover and marked 15 small (<10 cm max. length) individuals. Awnings substantially reduced temperature and desiccation extremes (see 'Results'). Mortality rates for March-April (when early-morning low tides and cool ambient temperatures mean desiccation is low) were compared to those from April to June, when temperatures and desiccation are much more severe (see 'Results').

\section{RESULTS}

\section{Biomechanical laboratory experiments}

Stress-strain curves from the tensometer tests were plotted for desiccated and hydrated thalli (Fig. 2). Desiccated stipes were stronger, but less extensible and more brittle than hydrated stipes. The work per volume required to break desiccated stipes was roughly twice that for hydrated stipes. However, the total work required to break desiccated stipes was 2 orders of magnitude less than that for hydrated stipes. Table 1 summarizes the material properties of the desiccated and hydrated stipes tested in the tensometer.

Under dynamic loading, all desiccated thalli began showing stress fractures after the first cycle and broke at the stipe in less than 60 cycles $(<45 \mathrm{~s})$ and 6 of the 10 thalli broke in 5 or fewer cycles $(<7 \mathrm{~s})$. None of the hydrated thalli broke after at least 800 cycles (10 min), when the experiment was stopped (Table 1).

Thalli used for the rehydration experiment reached a mean value of $0.36 \pm 0.02$ desiccated mass:hydrated mass after $6 \mathrm{~h}$ in the wind tunnel, comparable to the desiccation measured in the field (see next subsection). Desiccated thalli rehydrated quickly when submerged, resorbing approximately $15 \%$ of lost water after $0.5 \mathrm{~min}$ and $40 \%$ after $30 \mathrm{~min}$ of immersion (Fig. 3). The rehydrated thalli were placed in the dynamic loading apparatus to determine how fast stipes became flexible after immersion. However, the experiment was stopped after the first and second group of thalli ( 0.5 and 1 min immersion), because none had broken after 800 cycles. With $30 \mathrm{~s}$ of re-immersion, Fucus

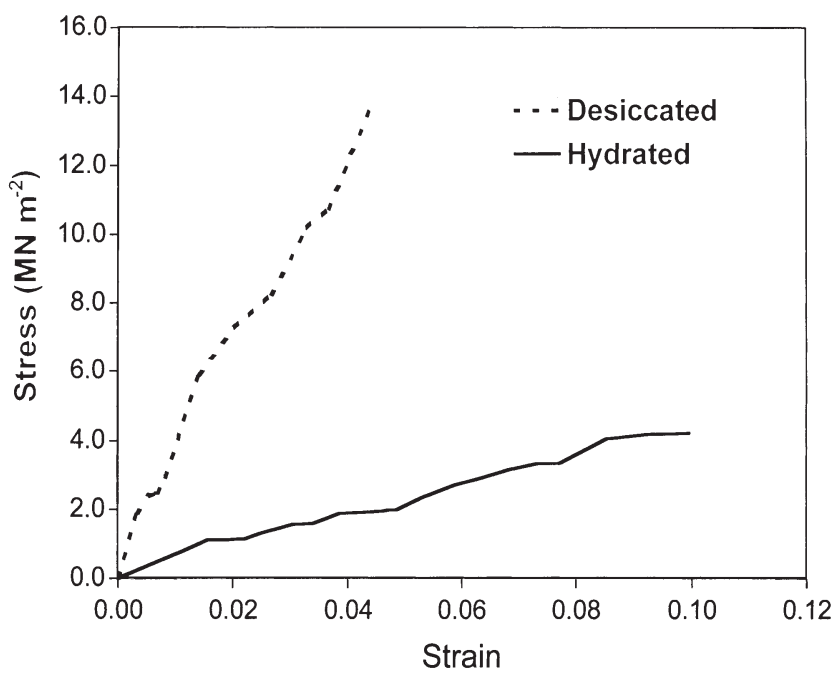

Fig. 2. Fucus gardneri. Representative stress-strain curves for desiccated and hydrated stipes. Lines end at stipe failure 


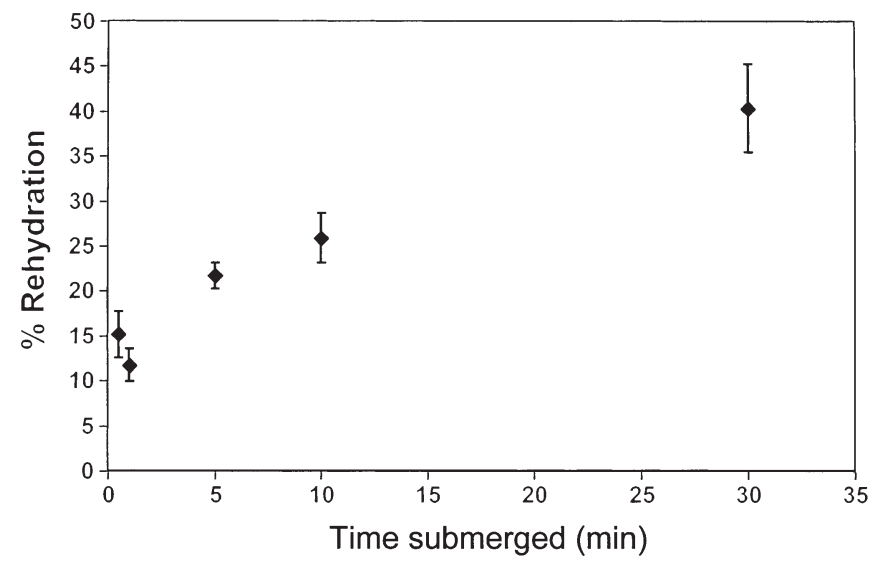

Fig. 3. Fucus gardneri. Mean $( \pm \mathrm{SD})$ rehydration over time. $\mathrm{N}=5$ for each data point gardneri stipes had become flexible enough to withstand the same dynamic loading that broke the earlier tested desiccated stipes.

\section{Field measurements}

Maximum water flow speed measured at the site during the August measurement period was $1.95 \pm$ $0.24 \mathrm{~m} \mathrm{~s}^{-1}$ (mean $\pm \mathrm{SE}, \mathrm{n}=3$ ).

The average daytime exposure of high-shore thalli increases from $5.5 \mathrm{~h}$ in March to $9.0 \mathrm{~h}$ in April, $11.4 \mathrm{~h}$ in May, and $11.7 \mathrm{~h}$ in June. Over the same period, air temperatures are steadily increasing (Fig. 4) especially in the high zone, with a corresponding reduction in relative humidity (Fig. 5). On a warm, sunny day in July (environmental data in Fig. 5), Fucus gardneri in the high- and mid-intertidal zones desiccated fairly rapidly. Thalli forming the

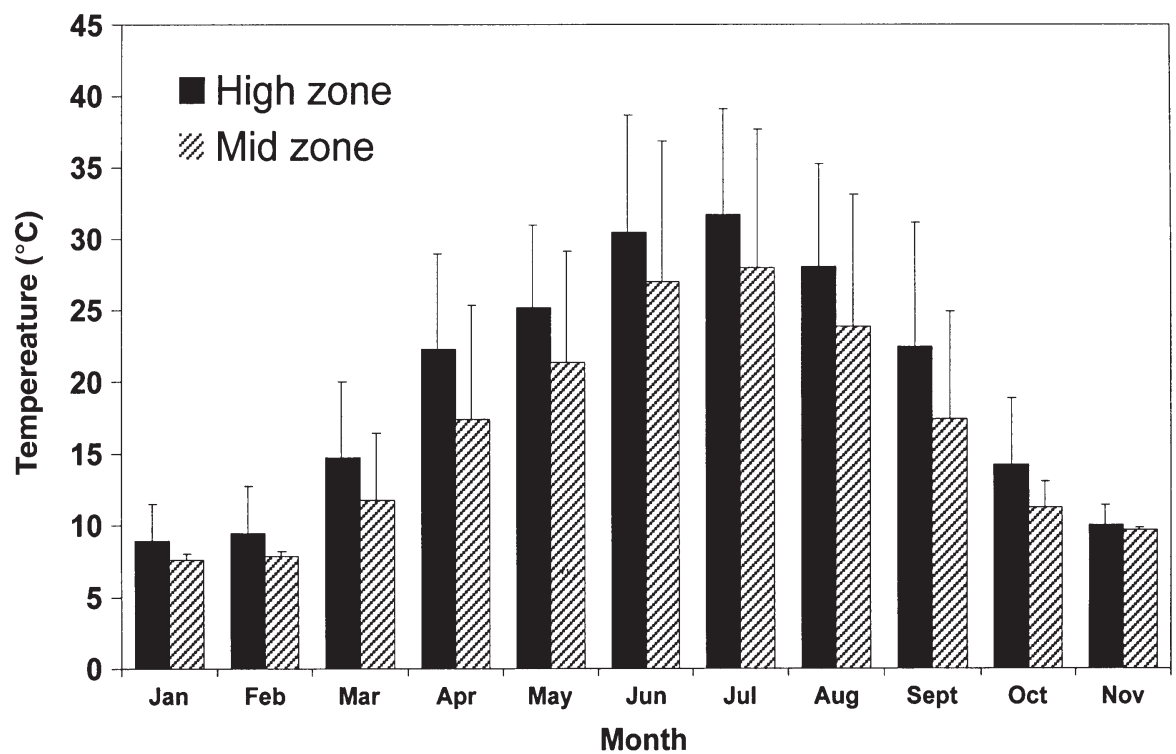

Fig. 4. Fucus gardneri. Mean maximum (+SD) temperatures in the high- and mid-intertidal at one site near Friday Harbor Laboratories, January through November 1999 canopy in the high zone reached a mean value of $0.36 \pm 0.08$ (mean \pm SD) field mass:hydrated mass after 9 h, just before re-immersion. Thalli below a canopy dried more slowly, but still achieved a ratio of $0.58 \pm 0.14$ after $9 \mathrm{~h}$. Thalli in the mid zone were emersed only for ca. $6 \mathrm{~h}$ and reached values of $0.44 \pm$ 0.15 (canopy) and $0.72 \pm 0.13$ (understory).

Although breaking strengths of thalli measured in the field varied, desiccated stipes required roughly twice the force per cross-sectional area to break than hydrated stipes (Student's $t$-test, $t=3.24$, df $=54, p=0.002$ : Fig. 6).

Windrows of Fucus gardneri washed up on beaches in July 1999 contained both thalli broken

Table 1. Fucus gardneri. Summary of mechanical properties of desiccated and hydrated stipes in laboratory experiments. $\sigma$ : stress on stipe at failure; $\varepsilon$ : strain on stipe at failure; $E$ : elastic modulus of the stipe at failure; $V$ : volume of the stipe; $W / V$ : amount of work per unit volume required to break the stipe; $W$ : total work required to break the stipe; na: not applicable. Values are means $\pm \mathrm{SE}, \mathrm{n}=10$

\begin{tabular}{|lccl|}
\hline Parameter & Desiccated & Hydrated & $t$-test \\
\hline$\sigma\left(\mathrm{MN} \mathrm{m}^{-2}\right)$ & $8.80 \pm 1.20$ & $2.35 \pm 0.43$ & $t=5.04, \mathrm{df}=18, \mathrm{p}<0.001$ \\
$\varepsilon\left(\left[l-l_{i}\right] / l_{i}\right)$ & $0.05 \pm 0.01$ & $0.09 \pm 0.01$ & $t=2.31, \mathrm{df}=18, \mathrm{p}=0.033$ \\
$E\left(\mathrm{MN} \mathrm{m}^{-2}\right)$ & $239.67 \pm 72.9$ & $38.30 \pm 9.12$ & $t=2.74, \mathrm{df}=18, \mathrm{p}=0.013$ \\
$V\left(\mathrm{~m}^{3}\right)$ & $7.61 \times 10^{-10} \pm 8.04 \times 10^{-11}$ & $2.49 \times 10^{-7} \pm 4.52 \times 10^{-8}$ & $t=5.49, \mathrm{df}=18, \mathrm{p}<0.001$ \\
$W / V\left(\mathrm{MJ} \mathrm{m}^{-3}\right)$ & $0.21 \pm 0.037$ & $0.10 \pm 0.037$ & $t=2.50, \mathrm{df}=18, \mathrm{p}=0.022$ \\
$W(\mathrm{~J})$ & $1.46 \times 10^{-4} \pm 2.17 \times 10^{-5}$ & $2.23 \times 10^{-2} \pm 4.48 \times 10^{-3}$ & $t=6.93, \mathrm{df}=18, \mathrm{p}<0.001$ \\
No. of cycles & $15.05 \pm 6.37$ & $>800$ & na \\
\hline
\end{tabular}



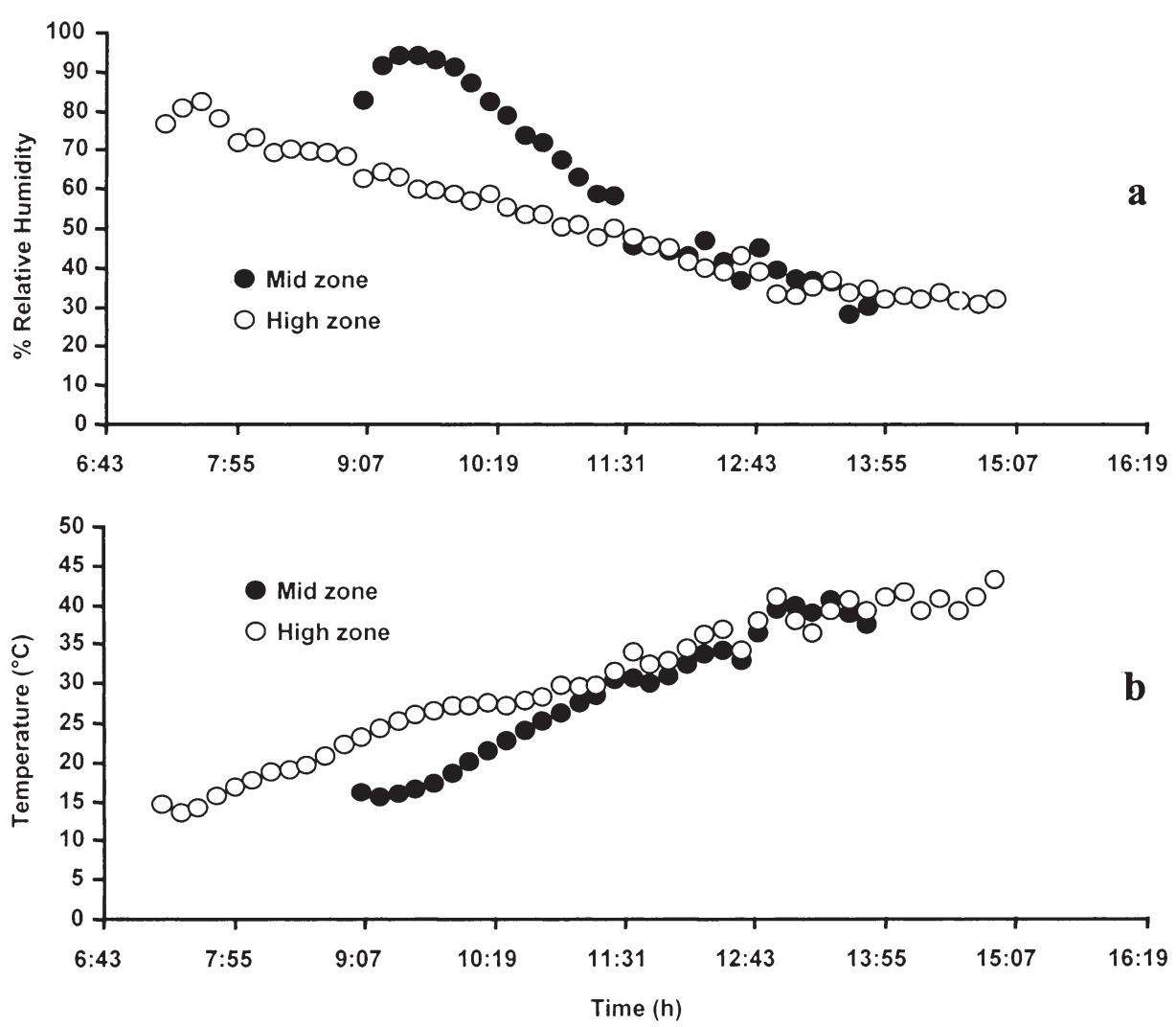

Fig. 5. Representative \% relative humidity and temperature in the mid- and high-intertidal zone near Friday Harbor Laboratories. Data were collected on 28 July 1999 and are typical for the summer months

at the holdfast and thalli broken at the stipe. The sizes of thalli in the flotsam were compared with those on the rocks nearby. Since it was impossible to distinguish a small thallus broken at the stipe from a portion of a larger thallus, analyses could only be done on drift thalli with the holdfasts attached. Relative abundances of different sizes varied between the shore and the drift thalli, suggesting differential mortality of different sizes $\left(\chi^{2}=267, \mathrm{df}=2, \mathrm{p}<0.001\right)$. There were far more large thalli and fewer small thalli in the drift than

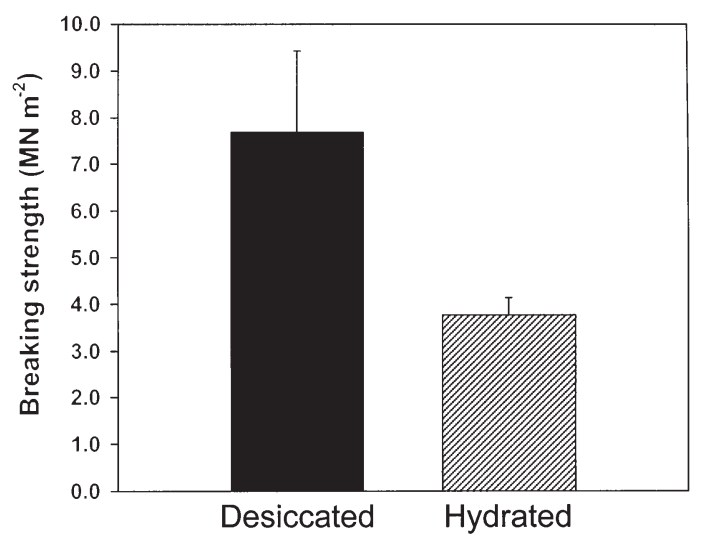

Fig. 6. Fucus gardneri. Stipe breaking strength (mean + SE) of thalli in the intertidal. $\mathrm{N}=13$ for desiccated thalli and 43 for hydrated thalli expected based on local size distributions on the rocks (Fig. 7).

Concurrent with the seasonal changes in physical conditions that relate to hydration status during low tides, Fucus gardneri in unmanipulated field populations and in the awning experiments consistently showed an increase in mortality rates through the spring months. In our field experiments (M.N.D. \& S.L.W. unpubl. data), only 41 of $\sim 200$ thalli were lost from mid-March to mid-May, but 91 of 200 were lost

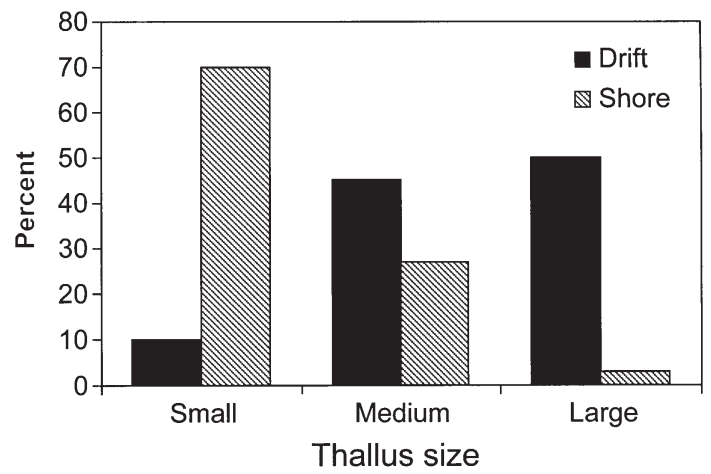

Fig. 7. Fucus gardneri. Percent of small $(<10 \mathrm{~cm})$, medium $(10$ to $20 \mathrm{~cm})$, and large $(>20 \mathrm{~cm})$ drift thalli with the holdfasts attached washed up on nearby beaches ('Drift') compared to living thalli in the intertidal ('Shore'). $\mathrm{N}=100$ per bar for drift thalli, 300 per bar for shore thalli 
from mid-May to mid-July $\left(\chi^{2}=28.20\right.$, df $=1$, $\mathrm{p}<0.001)$. The awnings substantially decreased temperatures (by 2 to $15^{\circ} \mathrm{C}$ on sunny days) and increased relative humidities (by 5 to $25 \%$ ) experienced by the thalli beneath them. On a sunny day in September (after the experiments ended and we could sample destructively), thalli under awnings retained 52 ( \pm 7 $\mathrm{SD}) \%$ of their hydrated mass, while those in the controls were much more desiccated (mean of $38 \pm 7 \%$, $t$-test on arcsine-transformed data, $t=5.47, \mathrm{df}=28$, $\mathrm{p}<0.001$ ). As in the natural populations, mortality in the late spring was significantly higher than in early spring in both treatments (Fig. 8: awnings $\chi^{2}=7.13$, $\mathrm{df}=1, \mathrm{p}<0.01$; no-awnings $\chi^{2}=11.70$, df $=1$, p < 0.001). However, the thalli protected from intense desiccation by the awnings suffered much lower mortality during both time intervals (March to April: $\chi^{2}=$ 18.94, df $=1, \mathrm{p}<0.001$; April to June: $\chi^{2}=38.89$, df $=$ $1, \mathrm{p}<0.001)$. The latter result could be an artifact of the awning thalli being protected from wave action by the awning structure, but the seasonal result cannot be explained in this way. The interaction illustrated in Fig. 8 suggests that the thalli exposed to both greatest desiccation (April to June, no-awnings) and perhaps the greatest flow (no-awnings) suffer by far the highest mortality. Based on these observations, we infer that increased desiccation could reduce $F$. gardneri's ability to withstand incoming waves and can reasonably be considered the cause of the increased mortality.

\section{DISCUSSION}

This study demonstrates that the stipe of Fucus gardneri becomes stronger, but brittle, when desiccated.

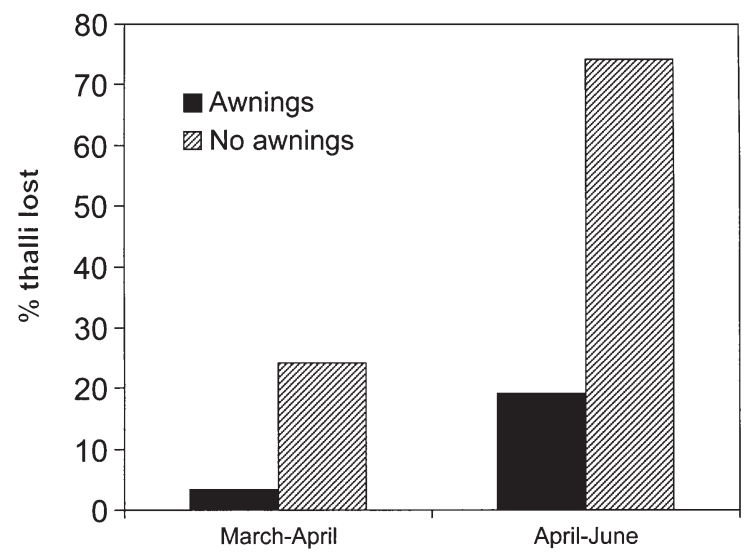

Fig. 8. Fucus gardneri. Percent of thalli lost during the March to April period compared to the April to June period, 1999, for awning and no awning treatments. $\mathrm{N}=120$
Stipe tensile strength increased when desiccated, due in part to a decrease in cross-sectional area. However, this increase in strength coupled with a decrease in extensibility makes the stipe brittle and therefore susceptible to crack propagation. While an increase in tensile strength probably mitigates drag forces pulling parallel to the stipe, our data suggest that the bending, not pulling, forces created by breaking waves are responsible for breaking the stipe. Breaking desiccated F. gardneri stipes requires more work per volume than hydrated stipes, but 2 orders of magnitude less total work (i.e. not normalized to stipe volume). If desiccated and hydrated stipes were the same volume, desiccated stipes would be tougher, requiring more wave energy to be damaged or dislodged, but as desiccation causes their volume to shrink considerably, under the same wave conditions a desiccated stipe is much more prone to breaking. The relatively small wave forces near FHL may be enough to damage or dislodge the thalli, although this effect would only be seen in the spring and summer, when desiccating conditions are likely because of the midday timing of low tides. This interaction of desiccation and waves could be a reasonable explanation for the $F$. gardneri rafts containing thalli with broken stipes.

Undamaged, hydrated Fucus gardneri stipes are relatively flexible; this can mitigate the effects of dynamic loading imposed upon them by water motion (Gaylord \& Denny 1997). Stipe failure for fully hydrated seaweeds is facilitated by nicks or cuts caused by abrasion and/or herbivory (Black 1976, Koehl \& Wainwright 1977, Denny et. al. 1989, Padilla 1993). Crack formation, facilitated by drying and caused by bending, probably weakens the stipe similarly; each of the desiccated stipes from the dynamic loading experiment developed stress cracks after the first cycle. However, F. gardneri thalli readily and rapidly take up water upon re-immersion. This capacity for rapid rehydration probably is critical to the survival and success of this species in the region. If rehydration were slow, waves accompanying an incoming summer tide could remove a significant proportion of the local populations. Instead, desiccated stipe failure is more likely to arise from impingement forces imparted by the first few waves accompanying tidal reimmersion (see Gaylord 2000 for a discussion on the importance of forces associated with wave impingement). If the stipes are not broken by these waves, stipe flexibility due to rehydration is likely to return. On many days, this rehydration may occur from small lapping waves (spray from waves is uncommon in these protected areas). However, the local frequency of boat traffic means that the first wave on a rising tide will sometimes be an abrupt boat wake; even a few such occurrences per month could probably significantly impact the population. 
Survival of F. gardneri is also a function of the dramatic changes in seasonal physical conditions; during the winter when wave action is much higher, desiccation is rarely a problem (except from occasional freezing) due to nighttime low tides, cool temperatures, and frequent rain.

The results of this study suggest a biomechanical mechanism for the seasonal pattern of mortality observed in an upper intertidal seaweed. Whether this mortality is critical in controlling the population size and growth rate is a subject of our ongoing research. This study provides an example of how 2 sub-lethal physical factors, desiccation and benign waves, can interact to cause mortality in an intertidal seaweed.

Acknowledgements. We thank M. Johnson, A. Freeman, and B. Mowrer for field assistance and A. Park for the dynamic loader illustration. The biomechanical portion of this study is based on research submitted in partial fulfillment of the requirements for the 2000 Physical Biology class at Friday Harbor Laboratories (R.N.H.). Advice from T. Daniel, D. Grünbaum, J. Kingsolver, K. Flick, D. Padilla, and B. Gaylord substantially improved the laboratory experimental design. This project was supported by grants from the California State University, Northridge Associated Students, and the FHL student fellowship (to R.N.H.), NSF grants \#OCE98196078 and \#0196078 (to S.L.W.) and NSF \#9901138 (to M.N.D.). R. Carpenter, P. Edmunds, and 3 anonymous reviewers made valuable comments on earlier versions of the manuscript. Contribution no. 2155 from Bodega Marine Laboratory, University of California, Davis.

\section{LITERATURE CITED}

Bell EC (1993) Photosynthetic response to temperature and desiccation of the intertidal alga Mastocarpus papillatus. Mar Biol 117:337-346

Bell EC, Denny MW (1994) Quantifying wave exposure: a simple device for recording maximum velocity and results of its use at several field sites. J Exp Mar Biol Ecol 181: 9-29

Biedka RF, Gosline JM, De Wreede RE (1987) Biomechanical analysis of wave-induced mortality in the marine alga Pterygophora californica. Mar Ecol Prog Ser 36:163-170

Black R (1976) The effects of grazing by the limpet, Acmaea insessa, on the kelp, Egregia laevigata, in the intertidal zone. Ecology 57:265-277

Editorial responsibility: Kenneth Heck (Contributing Editor), Dauphin Island, Alabama, USA
Blanchette CE (1997) Size and survival of intertidal plants in response to wave action: a case study with Fucus gardneri. Ecology 78:1563-1578

Carrington EC (1990) Drag and dislodgment of an intertidal macroalga: consequences of morphological variation in Mastocarpus papillatus Kützing. J Exp Mar Biol Ecol 139: 185-200

Chapman ARO (1995) Functional ecology of the fucoid algae: twenty-three years of progress. Phycologia 34:1-32

Davison IR, Pearson GA (1996) Stress tolerance in intertidal seaweeds. J Phycol 32:197-211

Denny MW, Daniel TL, Koehl MAR (1985) Mechanical limits to size in wave-swept organisms. Ecol Monogr 55:69-102

Denny MW, Brown V, Carrington E, Kraemer G, Miller A (1989) Fracture mechanics and the survival of wave-swept macroalgae. J Exp Mar Biol Ecol 127:211-228

Dudgeon SR, Johnson AS (1992) Thick vs thin: thallus morphology and tissue mechanics influence differential drag and dislodgement of two co-dominant seaweeds. J Exp Mar Biol Ecol 165:23-43

Gaylord B (1999) Detailing agents of physical disturbance: wave-induced velocities and accelerations on a rocky shore. J Exp Mar Biol Ecol 239:85-124

Gaylord B (2000) Biological implications of surf-zone flow complexity. Limnol Oceanogr 45:174-188

Gaylord B, Denny MW (1997) Flow and flexibility. I. Effects of size shape and stiffness in determining wave forces on the stipitate kelps Eisenia arborea and Pterygophora californica. J Exp Biol 200:3141-3164

Gaylord B, Blanchette CA, Denny MW (1994) Mechanical consequences of size in wave-swept algae. Ecol Monogr 64:287-313

Hawes I, Smith R (1995) Effect of current velocity on the detachment of thalli of Ulva lactuca (chlorophyta) in a New Zealand estuary. J Phycol 31:875-880

Hurd CL (2000) Water motion, marine macroalgal physiology, and production. J Phycol 36:453-472

Koehl MAR, Wainwright SA (1977) Mechanical adaptations of a giant kelp. Limnol Oceanogr 22:1067-1071

Koehl MAR, Wainwright SA (1986) Biomechanics. In: Littler ML, Littler DS (eds) Handbook of phycological methods. Ecological field methods: macroalgae. Cambridge University Press, Cambridge, p 292-313

Kraemer GP (1990) Influence of desiccation on the mechanical properties of Iridaea cordata (Rhodophyta). J Phycol 26:586-588

Padilla DK (1993) Rip stop in marine algae: minimizing the consequences of herbivore damage. Evol Ecol 7:634-644

Schonbeck MW, Norton TA (1980) The effects on intertidal fucoid algae of exposure to air under various conditions. Bot Mar 23:141-147

Submitted: June 4, 2001; Accepted: December 7, 2001 Proofs received from author(s): April 8, 2002 